\title{
THE PATTERN OF BEHAVIOUR OF RABBIT PUPS IN THE NEST
}

\author{
by
}

\section{R. HUDSON and H. DISTEL ${ }^{1}$ )}

(Institut für Medizinische Psychologie, Ludwig-Maximilians-Universität München, F.R.G.)

(With 6 Figures)

(Acc. 10-XII-1981)

\section{INTRODUCTION}

Rabbit pups are born after 31 days gestation in a rather immature state. They are naked, have sealed eyes and outer ears, are ectothermic and have poor motor coordination. By day 7 they are capable of limited orienting responses to auditory stimuli (Gotrlier, 1971), and may also perceive light changes (RIPISARDi $e t$ al., 1975) although they do not begin to open their eyes before day 10. Pups start to leave the nest when 13 to 18 days old (Zarrow et al., 1965; Mykytowycz \& Dudzinsky, 1972). By this time they are able to maintain a stable body temperature physiologically (Wishaw et al., 1979) and have much improved motor coordination.

When given the opportunity, doe domestic rabbits construct a furlined nest of grass in an underground burrow for their young (Dеuтsch, 1957). They leave their pups almost immediately after birth and, with occasional exceptions, only return to feed them once approximately every 24 hours (VenGE, 1963; ZarRow et al., 1965). The daily nursing period is very short, varying between does from 2 to 4 minutes (LiNCOLN, 1974). Rabbits apparently make little other provision for their young, and even fail to retrieve pups which stray from the nest (ZARRow et al., 1962).

While various aspects of the pups' physiological development and of rabbit maternal behaviour have been investigated, little attention has been given to the behaviour of the pups in the nest. Yet accounts of rabbit maternal behaviour suggest that the pups must maintain an adequate

1) We would like to express our thanks to Prof. J. Aschoff, Prof. E. Pöppel, Dr W. FRIES and T. ROENNEBERG for critically reading the manuscript and for helpful discussions, and to the Deutsche Forschungsgemeinschaft for supporting this work (Di 212/2-1). 
body temperature without being brooded, and must obtain sufficient nourishment during brief, once daily nursing periods.

It is the purpose of this study to report on the behaviour of rabbit pups during the time they are confined to the nest. Their daily cycle of prenursing aggregation and exposure from the nest material and postnursing digging and dispersal will be described and its adaptive significance discussed.

\section{ANIMALS AND METHODS}

Rabbits, Oryctolagus cuniculus (L), of an established chinchilla strain (Chbb) were obtained from Thomac (Bibfrach, F.R.G.), and bred in our facilities. Twenty-two litters reduced to six pups each were used. Six litters were observed with minimal interference until post-natal day 14 to establish the normal pattern of the pups' behaviour. Sixteen additional litters raised under the same basic conditions were used for behavioural tests.

The pups were raised in a plexiglass nest box which was connected by a plexiglass passage to a standard rabbit cage (Fig. 1). Passage and nest box floors were lined with porous plaster board $1 \mathrm{~cm}$ thick, which absorbed the pups' urine readily. This was renewed for each litter. A sliding door between the passage and home cage served to separate the mother from her young. The animals were kept under a constant 12 hour light/dark cycle. Hay, water and food pellets were provided ad libitum. The ambient air temperature was $20^{\circ} \mathrm{C} \pm 1{ }^{\circ} \mathrm{C}$, and the relative humidity luctuated between 40 and $60 \%$. However, the air temperature in the nest box was $2-3^{\circ} \mathrm{C}$ higher due to the heat produced by the pups, and repeated local measurements indicated a variation of air temperature within the box as shown in Fig. 1.

Does were allowed at least one week to become accustomed to the new environment and to build a nest. After they had given birth and left the nest for one hour the does were locked out by closing the sliding door. All litters were born in the afternoon or during the night, and the following day was counted as day 1. For the next two weeks the experimental method of ZARROW et al. (1965) was followed, and does were allowed access to the nest box only twice a day; in the morning one hour after the lights went on, and in the evening one hour before they went off. The passage door was closed again after 10 minutes, or if the doe nursed, 5 minutes after her return to the home cage.

\section{Observational litters ( 1 to 4 ).}

To record the behaviour of the pups a Video system was installed with the camera viewing the nest box from above. The behaviour was filmed for ten 10-minute periods each day: 12, 6,2 and 1 hour before nursing, 5 minutes before, during and 5 minutes after nursing, and 1, 6 and 10 hours after nursing. Births were also filmed. Nursing always occurred in the morning when the doe was given access to the nest box by the experimenter. The second access was given 10 hours later. Two minutes of each recording were used for quantitative analysis of the degree of exposure of the pups from the nest material. This was estimated by allocating a visibility value to various parts of the pups' bodies (one ear $=1$, entire head $=2$, back or belly $=2$, tail $=1$ ) and adding up the values of visible body parts of the whole litter.

The location of the pups in the nest was also analysed over the first 12 days. For this the nest box floor was divided into six equal areas 15 by $13 \mathrm{~cm}$ (Fig. 1), and points were allocated in the middle of each area and in the center of the nest where the area borders met. The presence of a pup at any one of the resulting cight points was scored. If a pup was between points the score was shared, and if it was near the corncr or edge of the box 
the nearest point received the score. When the pups were totally covered, local movements of the nest material were used to estimate the position of the pups.

The approximate milk consumption was also measured in the observational litters and in some of the test litters. To minimize disturbance, the pups were weighed 1 hour before and 1 hour after nursing. The data from the observational litters provided the base line against which the performance of test litters was analysed using the t-test for dependent samples (HAYs, 1963).

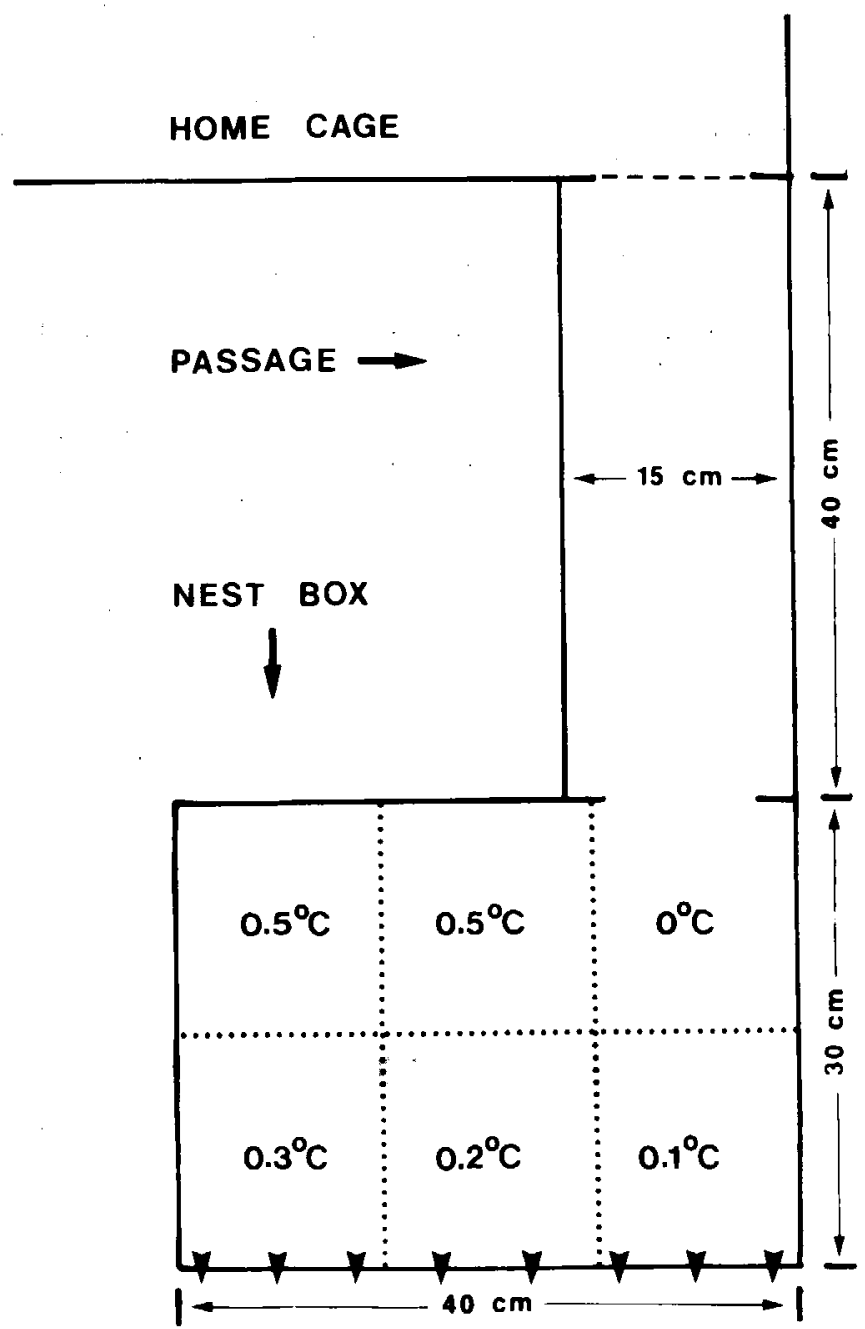

Fig. 1. Ground plan of the observation cage. The dashed line between passage and home cage represents the sliding door, and arrow heads the air holes near the top of the nest box. Dotted lincs show the areas into which the nest box floor was divided for recording the location of the pups. Local variation of the air temperature within the nest is indicated. 
In two additional litters ( 5 and 6) the behaviour of pups and doe was observed and recorded from beneath through the plexiglass after the plaster floor was removed.

\section{Test litters.}

The behaviour of pups before nursing was further investigated in five litters. In two of them (A, B), a different pair of pups was moved each day $20 \mathrm{~cm}$ away from the littermates immediately before nursing. In three more litters $(C, D, E)$, the effect of covering the pups with nest material immediately before nursing was observed, and in one litter (C) tested every second day. Daily milk intake was measured in litters A, B and C.

In five more litters ( $\mathrm{F}$ to $\mathrm{J}$ ), the post-nursing behaviour of pups was investigated under various stimulus conditions, i.e., limited contact with the doe, covering the pups with nest material, exposure to the smell of urine, and contact with urine, water or a cold surface.

The influence of local variables in the nest was tested in four litters ( $\mathrm{K}$ to $\mathrm{N}$ ). In two of them the plaster floor with covering nest material was rotated $180^{\circ}$ immediately after nursing on day 5 and turned back again on day 8 . In two other litters temperature differences in the nest (Fig. 1) were eliminated on day 4 by blocking the air holes and entrance.

Finally, the nest boxes of two litters (K, L) were detached from the doe's home cage and the pups raised in a separate room in the dark. The does were brought in every day just before nursing, except on days 5 and 8 when the pups were not allowed to nurse. On these and the following days ( 6 and 9 respectively), the exposure of the pups from nest material was recorded on Video following a schedule similar to that described above. Pups were only exposed to light on these days during Video recording.

\section{RESULTS}

\section{Behaviour of the doe.}

All does built a fur-lined nest of hay in the nest boxes. Parturition lasted about 10 minutes only, and the does rapidly licked each pup as it was born. After giving birth the does nursed their pups for less than a minute, and then abruptly left the nest box without returning during the following hour.

The next morning, as soon as the dividing door was raised, the does entered the nest and spent approximately 5 to 10 minutes nursing. However, on subsequent days does only ever spent between 2.3 and 2.9 minutes nursing. During the 10 minutes of evening access they sometimes entered the nest box briefly but paid no attention to the pups.

While nursing, does kept their body very still. Even when they trod on a pup they did not adjust their stance despite vigerous wriggling and vocalization by the pup. Does stood hunched over their litter, their hind feet and tail pressed firmly to the floor, enclosing the pups within a small area. As the pups grew this posture altered. By day 7 or 8 , does raised their hindquarters off the ground and stretched out more (Fig. 2). They occasionally nuzzled nest material away, especially from very young pups, and sometimes bricfly licked them. 

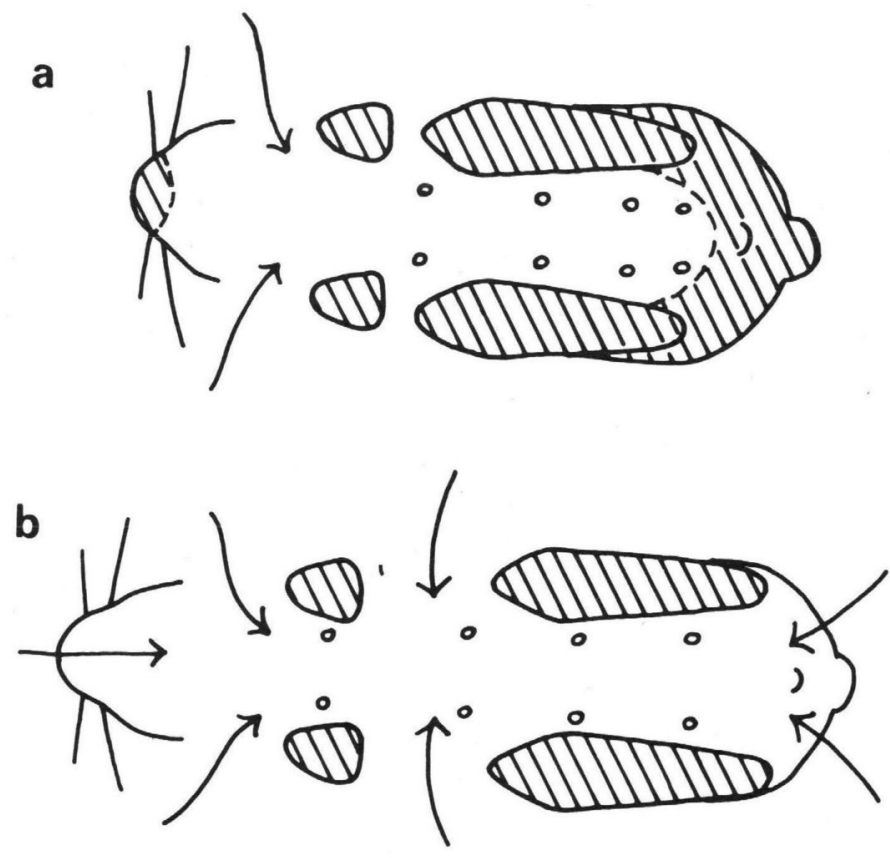

Fig. 2. Schematic representation of the nursing postures of the doe viewed from beneath. Hatched areas indicate the body parts in contact with the floor, and arrows the gaps allowing access to the doe's belly. (a) Hunched posture before day 7 or 8, (b) extended posture after day 7 or 8 .

Just before leaving, does deposited a few faecal pellets in the nest box, and sometimes made an attempt to clean the nest box entrance by pushing scattered material back into the nest.

\section{Behaviour of the pups.}

After birth the newborn pups were very active and vocal, and immediately tried to suckle. As soon as their mother left, they very quickly burrowed under the nest material and became well covered.

Apart from some variation between litters on day 1, the pattern of behaviour of the pups remained essentially unchanged until day 13 , when they started to leave the nest box. This pattern was clearly associated with the time of nursing and divided naturally into four main periods: nursing itself, a post-nursing period of about 15 minutes, a period of about 22 hours between nursings, and a pre-nursing period of one to two hours. 


\section{Nursing.}

Except on day 1, by nursing time the pups were tightly grouped together, were restless and almost bare of nest material (Fig. 3a). When the doe entered the nest they became highly excited, reared their heads up and often vocalized. Viewing the behaviour of a litter from beneath, showed that pups were able to locate the nipples within seconds by moving their heads rapidly from side to side through the doe's belly fur. Nursing terminated abruptly with the doe jumping out into the passage. The pups dropped immediately from their mother's nipples, and no pup was ever dragged beyond the boundary formed by the nest material.

\section{Post-nursing urination and dispersal.}

Following an approximately 30 second period of quiescence after nursing, the pups urinated, started vigerously digging and burrowing under the nest material and dispersed throughout the nest (Fig. 4). To check the degree of dispersal, location scores (see Methods) from each litter were averaged and compared to a theoretical even distribution using the chisquare test (SiEgel, 1956). No significant difference was found between these distributions $\left(\chi^{2}=3.67\right.$, d.f. $\left.7, \mathrm{p}=0.9\right)$.

During digging pups adopted a posture not shown at any other time. While remaining upright and bracing their hindquarters on stiffly extended hind legs, they paddled vigerously with their forepaws. The burrowing movements were also distinctive. Pups pushed their heads under the nest material, and by raising head and forequarters, tipped the material back over themselves. Within one or two minutes of nursing the pups became well covered (Fig. 3b).

Regular inspection of nest floors during the day indicated that pups only rarely urinated at other times. Occasionally very young pups urinated during nursing, and older pups sometimes after they had burrowed some distance. As the pups burrowed they fluffed up the nest material trodden down by the doe during nursing, and the damp hay at the urination site became mixed with drier nest material.

Despite the vigerous post-nursing dispersal pups never strayed from the nest. They frequently approached the nest entrance but as soon as they touched the bare floor of the passage they turned and crawled back into the nest.

\section{Reaggregation between nursings.}

Post-nursing dispersal and burrowing lasted no longer than 15 minutes. After this time two pups meeting one another usually remained 

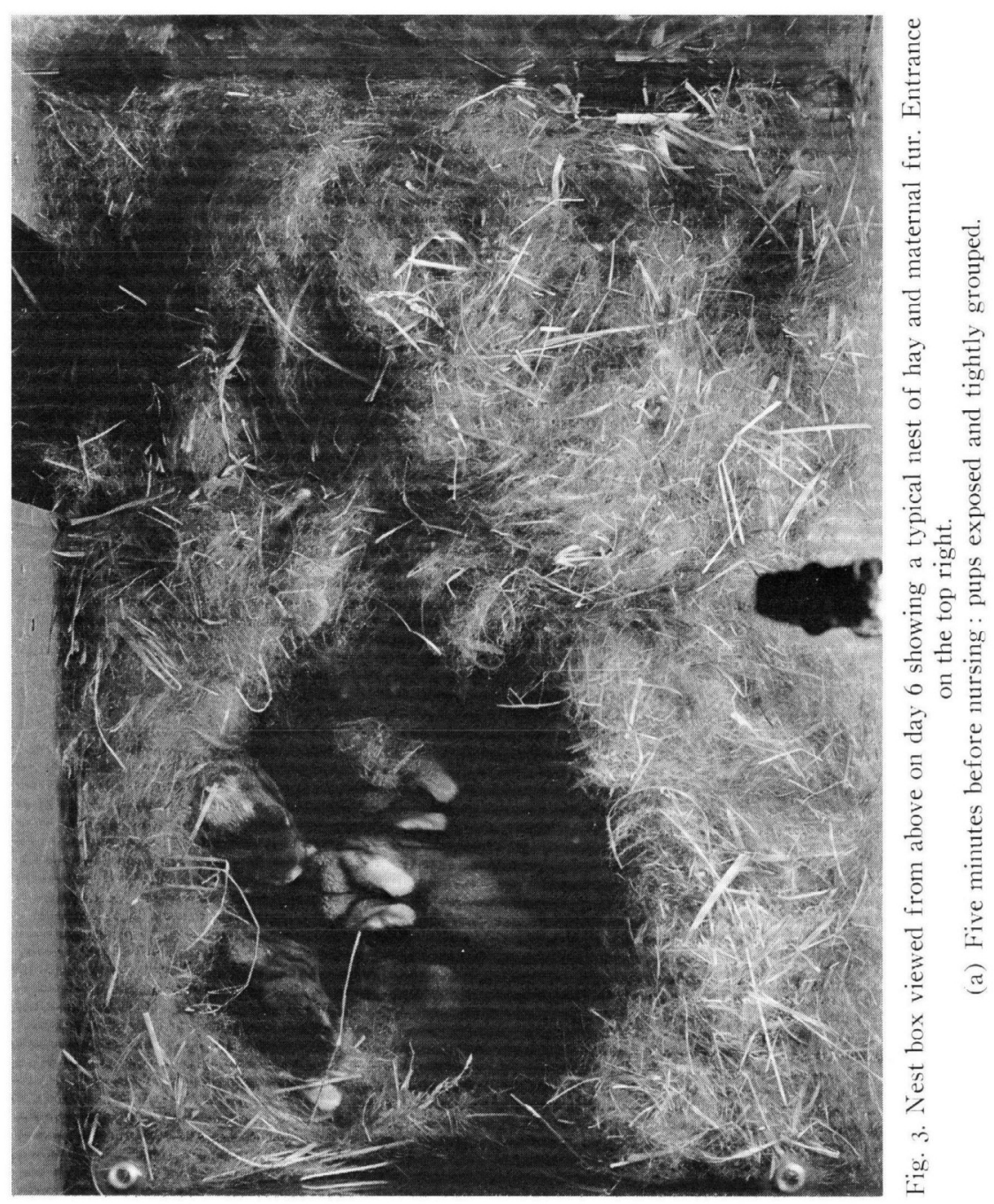


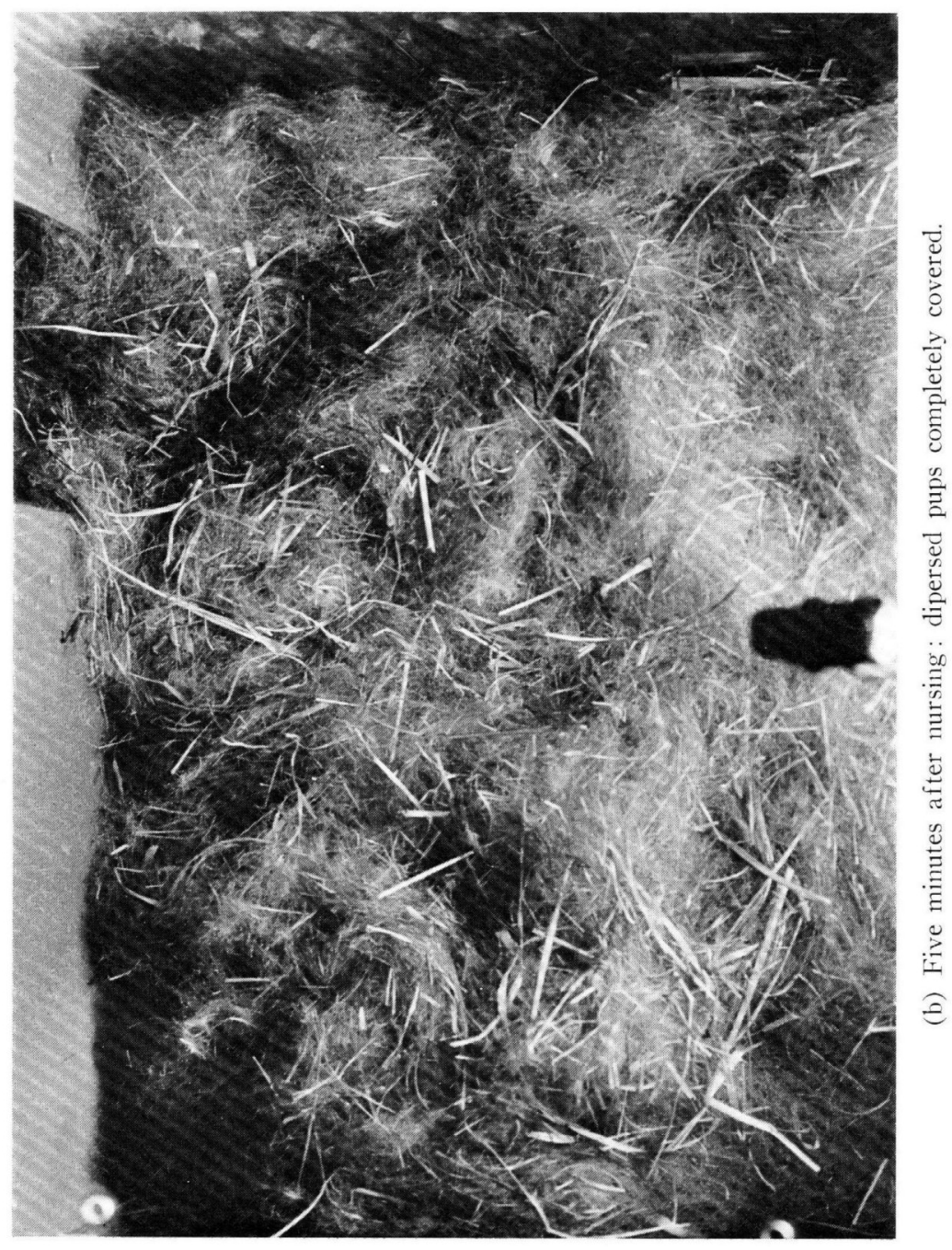




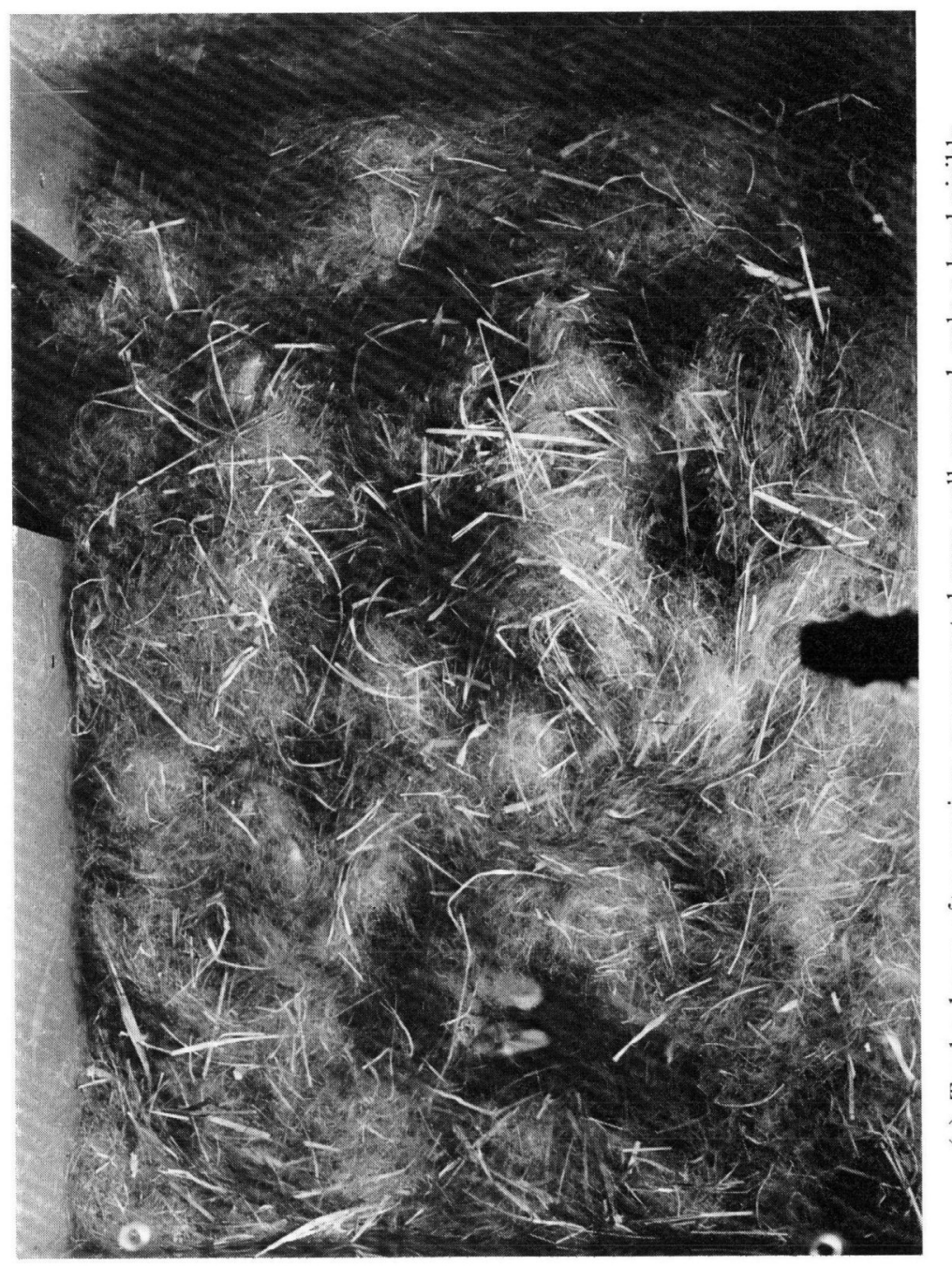

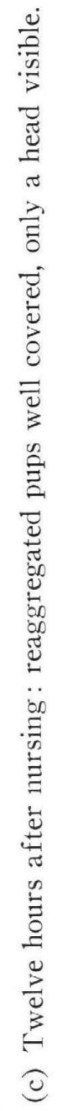


together. They circled around and burrowed under each other, apparently trying to maximize body contact. The pairs usually broke up after a few minutes, and the pups continued crawling around the nest until they encountered another pup or a group. Larger groups were more stable, and this resulted in the formation of a singly huddle within about 30 minutes. During the day these groups remained well covered (Figs. 3c

\section{Litter}
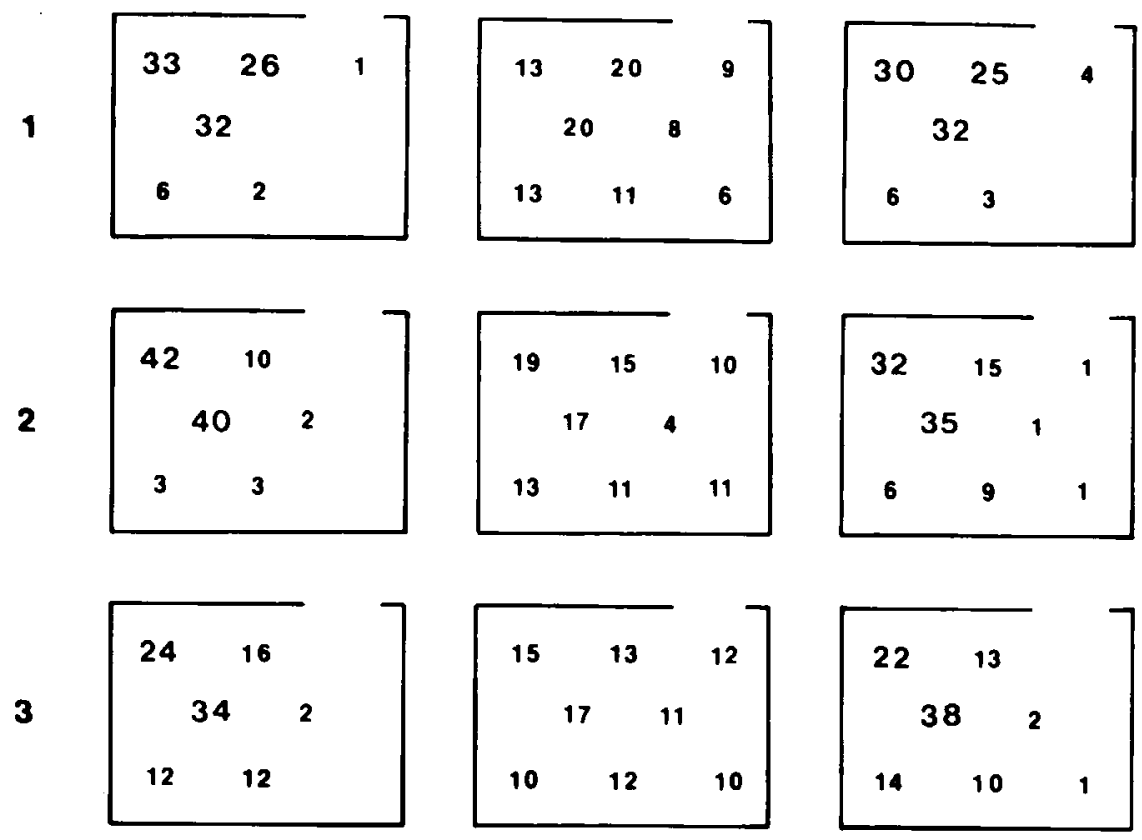

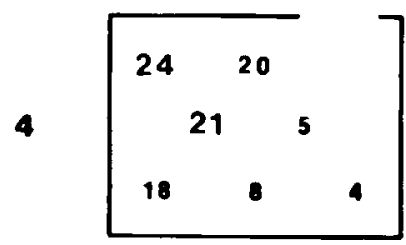

5 min before

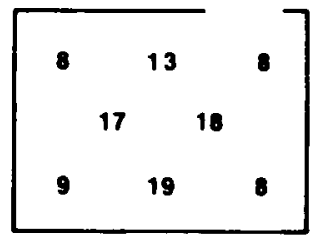

5 min after

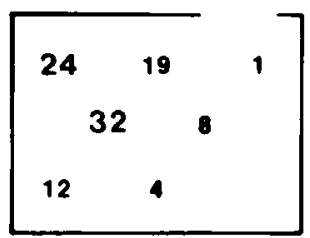

12 a ater

Time in relation to nursing

Fig. 4. Local distribution of pups (litters 1-4) in the nest box in relation to the time of nursing during the first 12 days. Numbers indicate the relative frequency $(\%)$ of the pups locations. The position of the numbers correspond to the eight recording points of the nest box. Scores above $20 \%$ arc emphasized. 
and 5) and pups were not very active. Huddling groups finally came to rest in the warmest part of the nest, the top left corner (c.f. Fig. 1 and Fig. 4). Sometimes pups on the edge broke away and crawled around the nest but usually rejoined the group within a few minutes. When at 12 hours after nursing, location scores were averaged and compared to an even distribution as above, a significant difference was found $\left(\chi^{2}=44\right.$. 1 , d.f. 7, $\mathrm{p}=0.001$ ).

\section{Pre-nursing huddling and exposure.}

The behaviour of the pups before nursing could be distinguished from their behaviour at other times in three ways. They were more exposed
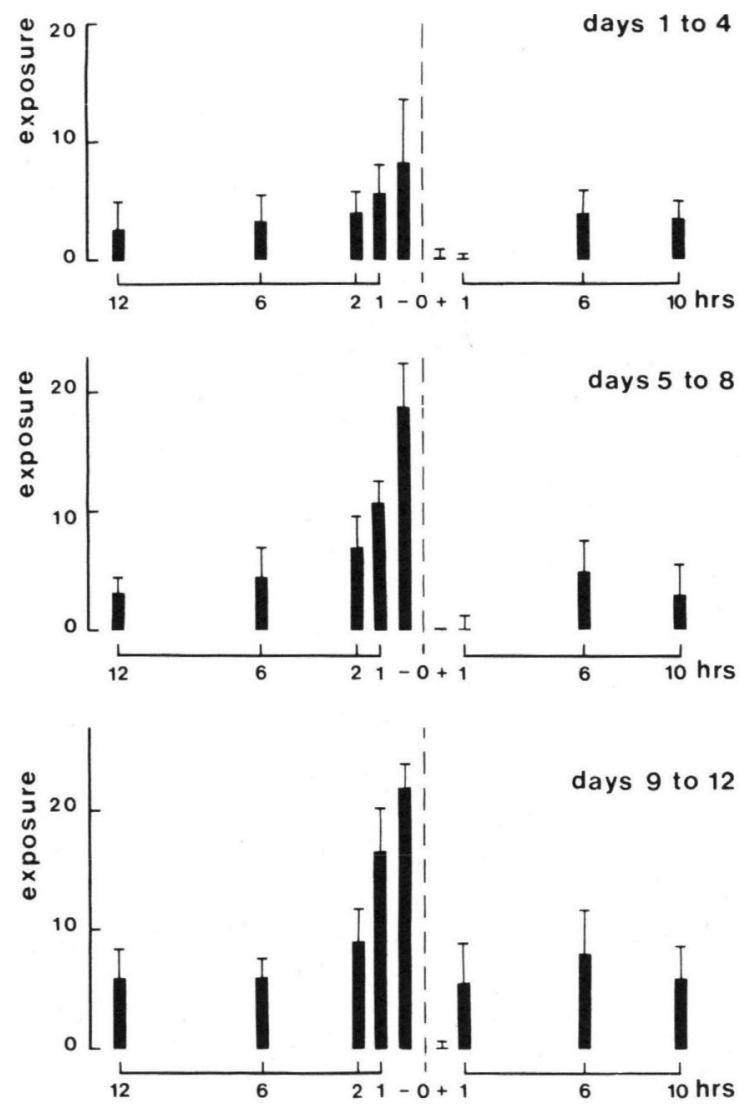

Fig. 5. Exposure of pups from nest material before and after nursing at different ages. Bars represent median scores of exposure in the four observational litters for each fourday period. Variation is indicated by semi-inter-quartile ranges. Dashed lines indicate the nursing time, and bars immediately to the left and right, exposure at five minutes before and after nursing. 
(Fig. 5), they were more tightly grouped (Fig. 4), and they were very active. Covering nest material gradually fell away so that an hour or so before nursing the pups were almost bare (Figs. 3a and 5).

To compare the exposure and degrec of aggregation of pups 5 minutes before nursing, with 5 minutes after, 6,12 and 18 hours after nursing the exposure and dispersal scores for each litter were summed and the Fricdman two-way analysis of variance by ranks (SIEGEL, 1965) was used. Pups were significantly more exposed $\left(\chi \mathrm{r}^{2}=15.2\right.$, d.f. $\left.4, \mathrm{n}=4, \mathrm{p}=0.01\right)$ and significantly more tightly grouped $\left(\chi \mathrm{r}^{2}=13.4\right.$, d.f. $\left.4, \mathrm{n}=4, \mathrm{p}=0.01\right)$ at this time.

Tests on aggregation and pre-nursing exposure.

In all observational litters, only on five occasions were individual pups away from the huddle at nursing time. None of the seven pups involved succeeded in nursing. These observations were more systematically tested in two litters (A, B) by displacing a pair of pups just before nursing. Does ignored the small group formed by these pups and positioned themselves directly over the huddle. As measurements of milk intake indicate (Table 1), young displaced pups completely failed to nurse. However, after day 7 nursing appeared unaffected by the displacement procedure. Although very young pups were well able to reach the doe they could not burrow under her, whereas by day 7 her changed nursing posture allowed better access.

To test the importance of pups being uncovered before nursing, the behaviour of three litters $(C, D, E)$ and does was observed after the prenursing huddle had been covered experimentally with nest material. The does attempted to uncover the young by nosing away the nest material, and this often resulted in the pups being pushed away and dislodged from the nipples. It also increased the time spent in the nest by an average of 6.7 minutes. Measurements of milk intake of litter C, covered every second day, indicated that until day 6 milk consumption per pup was less than half that of the undisturbed litters (Table 1) and only reached normal values by day 8 .

\section{Tests of post-nursing urination and digging.}

It was observed that the displaced, unfed pups of litters $A$ and $B$ urinated after the doe's departure but did not show the specific postnursing digging and burrowing. This led to a series of experiments to test the conditions for urination (litters F and $G$ ) and digging (litters, H, I, J).

When pups removed before the doe's entry were returned to the group after her departure they urinated although they were less aroused 
R. HUDSON \& H. DISTEL

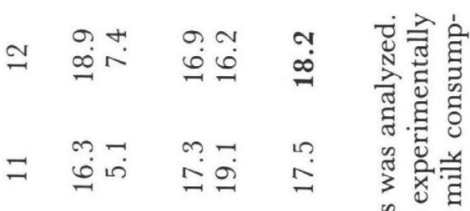

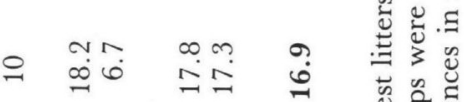
苍舒

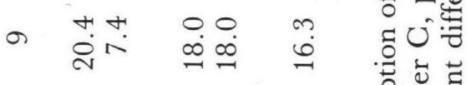

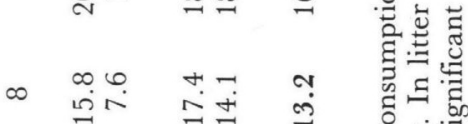

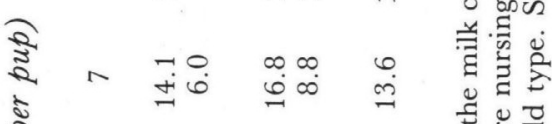

है

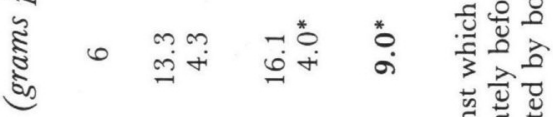

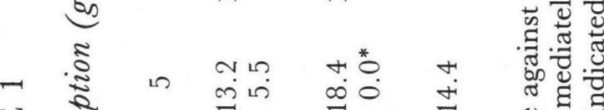

II है

造

$\forall$ 㟧

है $0 * \infty$ o

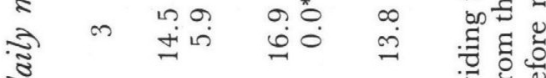

8 वे

๙

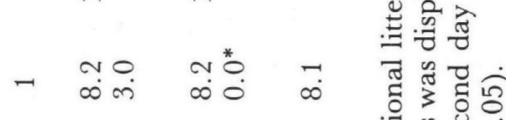

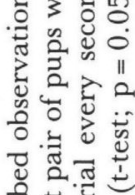

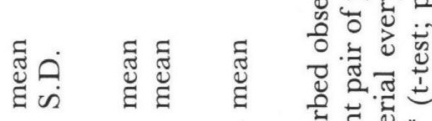

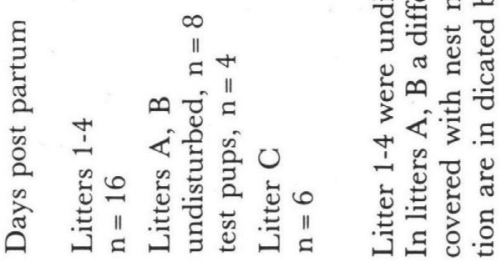


than unfed pups which had unsuccessfully tried to nurse. Cotton swabs soaked in fresh pup urine and held near the pups' noses did not induce urination. However, pups could be quickly and reliably induced to urinate up to day 8 by wetting them with urine or water, or by placing them on a cold, dry surface.

When the nipples of a doe were taped over so that the pups could not obtain milk during the doe's nursing visit, neither urination nor digging occurred after her departure although the pups were left in an extremely aroused state. However, after the tape was removed and normal nursing permitted, post-nursing digging and urination were as usual. Covering the pups immediately after nursing when they were still exposed, or removing the nest material entirely, did not affect the stereotyped digging behaviour.

\section{Choice of aggregation site.}

To test the possibility that the nursing site was marked locally, e.g., with urine, and that this helped the pups to reaggregate there, the nest floor and material were rotated $180^{\circ}$ in litters $\mathrm{K}$ and L. Neither this, nor later turning the floor and nest material back to the original position caused any change in the litters' choice of aggregation site, at the corner furthest from the entrance and air holes.

To determine whether the pups were influenced by temperature differences within the nest (Fig. 1), the behaviour of two more litters (M, N) was tested after the door and the air holes were blocked. This resulted in an even, but slightly higher ambient nest temperature. Litters now changed theit aggregation sites, and over the following days used the whole nest area.

\section{Independence of the behavioural cycle.}

To test to what extent the daily behaviour pattern was dependent on the time of the last feed or on external cues from the laboratory, e.g., the light/dark cycle, and from the doe, e.g., sound or vibration of the cage, the nest boxes of two litters $(\mathrm{O}, \mathrm{P})$ were detached from the doe's home cage and the litters were raised in an isolated, dark room. In both litters nursing was twice omitted, and measurements of exposure from nest material indicated that the pups became uncovered 22 hours after the last nursing in the same way as normal litters. However, since nursing did not occur, they remained exposed for several hours and failed to show the characteristic post-nursing digging and burrowing behaviour although they gradually became covered (Fig. 6). At 47 hours after the last nurs- 

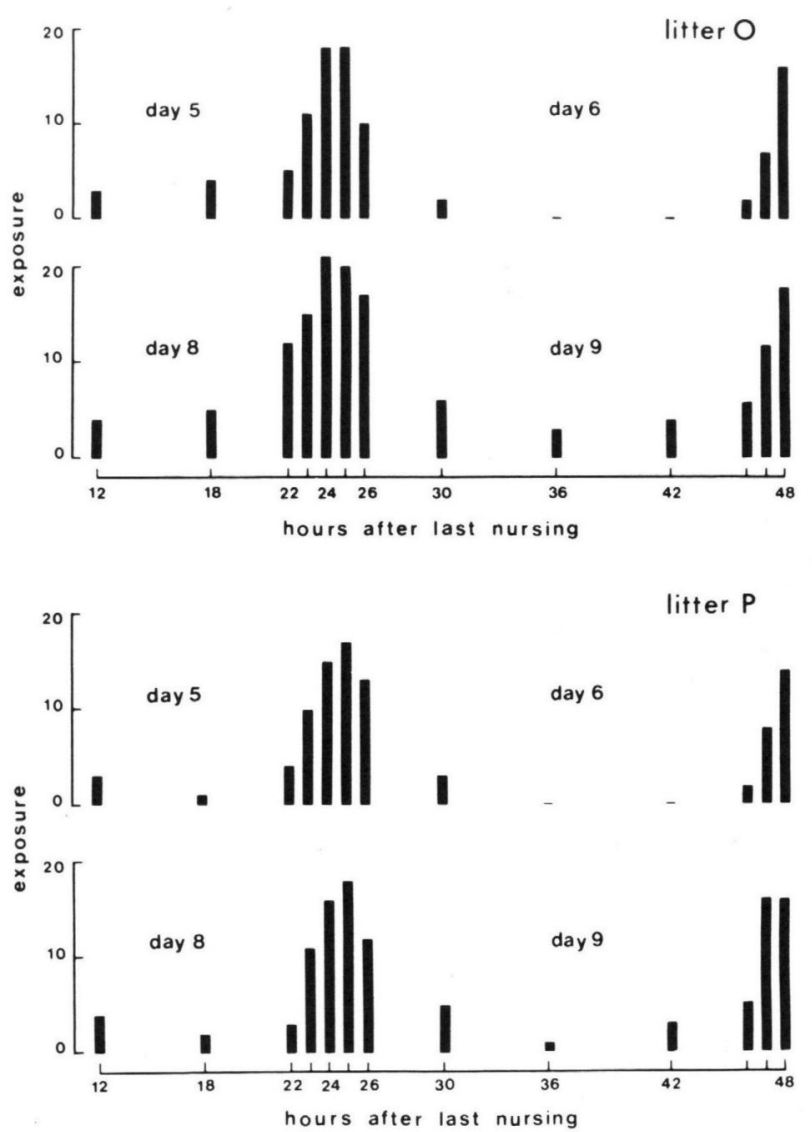

Fig. 6. Pattern of the pups' exposure from nest material when nursing a as omitted on days 5 and 8 in two litters. Pups remained exposed for several hours; they became exposed again on days 6 and 9 in anticipation of the nursing time. Bars represent actual scores of exposure.

ing, i.e. one hour before the usual nursing time, they again became exposed from nest material. Nursing was then permitted, and post-nursing behaviour appeared normal.

Changes with age.

Besides the observation mentioned above that pups on day 1 were rarely exposed from nest material before nursing, a noticeable change in the degree of pre-nursing exposure occurred over the subsequent 11 days (Fig. 5). This was largely due to the increasing size of the pups. However, they also became better-furrcd during this time. 
The pups started mouthing and nibbling the nest hay on about day 8 , and by day 11 or 12 were eating so much hay that the nest diminished visibly. It was mentioned above that does deposited faecal pellets in the nest at nursing time. The reaction to these pellets was observed from beneath. From day 1 pups showed brief excitement if their nose came into contact with pellets, particularly if fresh. Around day 8 they started nibbling at them, and by day 10 were eating whole pellets, possibly thereby gaining gut flora necessary for the digestion of plant food.

On day 10 and 11 the pups opened their eyes, and about this time does stopped cleaning the passage. However, the behavioural cycle of prenursing aggregation and uncovering, and post-nursing burrowing and dispersal continued unchanged until day 12 . On day 13 the pups started leaving the nest and awaiting the arrival of their mother at the cage end of the passage. By about day 15 the pups spent most of the day packed tightly together in the passage.

\section{DISCUSSION}

Rabbits are fugative animals and are heavily preyed upon. In contrast to their normal living burrows, the nursery burrow has a single entrance which the doe blocks after every visit (Mукутоwycz, 1968). Presumably the less time the doe spends in this burrow the less chance there is of predators trapping her or finding the young (ZARRow et al., 1965).

Reports of the maternal behaviour in the wild (Мукутоwycz, 1968), and in the domestic rabbit under seminatural conditions (DEuTsch, 1957) are consistent, and a direct comparison suggests that the maternal repertoire has been essentially unaffected by domestication (KRAFT, 1979a, b). It is well established and confirmed by our observations, that rabbit does only nurse once a day, and then for only about three minutes (Deutsch, 1957; Venge, 1963; Zarrow et al., 1965; Mykytowycz, 1968; LinCOLN, 1974). Brief nursing is partly achieved by the doe's ability to actively eject milk (Cross \& Harris, 1952; Lincoln, 1974). However, our observations suggest that the thermoregulatory abilities of the pups, and their anticipation of the nursing time also contribute to reducing the time the doe must spend with the young.

The major finding of this study is that rabbit pups show a daily sequence of behaviour which remains essentially unchanged until they leave the nest. They huddle tightly together before nursing and become exposed from nest material. Triggered by nursing, they urinate simultaneously, and disperse throughout the nest by digging and burrow- 
ing under the nest material. They then reaggregate in the warmest area of the nest, and remain covered until the next nursing time. Interestingly, a daily cycle of nursing behaviour has also been reported in the North American snowshoe hare, which has precocial young born above ground. The young hares gather together at dusk for the daily nursing just before the doe's arrival. After nursing they disperse and spend the following day hidden in the vicinity (Rongstad \& TESTER, 1971).

Rabbit pups may increase their chance of obtaining a proper feed when they are well exposed before nursing and grouped tightly together, as suggested by our experiments. Exposure may also shorten the doe's stay as she need not search for the pups and may assume the nursing posture immediately. The type of nest material and the quality of the nest affects the growth rate of the young (WORDEN \& LFaHY, 1962), and possibly also the degree of prenursing exposure.

Newborn rabbits must maintain an adequate body temperature although lacking the physiological means of the adult (Wishaw et al., 1979). Single pups rapidly loose body temperature (JEDDI, 1971), and like other altricial young (Leonard, 1974; Alberts, 1978), they improve their insulation by huddling together and thus reducing the overall body surface. Their ability to detect small thermal differences (SArinoff et al., 1976) was demonstrated in our study by the aggregation of the litters in the warmest area of the nest.

After nursing most young mammals become quiet and fall asleep (Rosenblatt, 1976). Rabbit pups are unusual in that they show only a very brief period of post-nursing quiescence followed by a burst of vigerous digging and burrowing. As a result of this activity pups quickly regain a cover of nest material, the insulating quality of which may be improved by being fluffed up and mixed. However, tests indicated that this behaviour is not goal oriented, but rather triggered by the nursing act.

Simultaneous urination may also contribute to thermoregulatory efficiency. The pups become wet from the urine but dry quickly when given the chance to burrow through nest material. Thus, synchrony may ensure that pups need not break away from the group several times a day in order to dry quickly. Tests and observations on unfed pups indicated that the sensation of cold caused by contact with urine induced them to urinate together with the litter.

The physiological mechanisms regulating the daily pattern of behaviour in the newborn pups are not yet clear. Pre-nursing uncovering exposes the newborn rabbits to ambient temperatures well below their 
thermal neutral range which is $35^{\circ} \mathrm{C}$ on day 1 (Hull, 1965). It has been demonstrated that rabbit pups have an especially large store of brown adipose tissue which is used for non-shivering thermogenesis in response to cold (Hull \& Segall, 1965a). This response appears to be mediated by the sympathetic nervous system (Hull \& SEGALl, 1965b). We may suppose that urination and energy conservation during the post-nursing period are under parasympathetic control (GANONG, 1971). Thus a daily change from a predominantly sympathetic to a predominantly parasympathetic mode may occur with nursing.

The anticipatory uncovering by the pups before nursing does not appear to be a simple consequence of the absence of food in the gut. The isolated litters deprived of one nursing gradually became covered with nest material, but uncovered again before the usual time of nursing the following day although care was taken to exclude all external cues. Similarly, it has been found that adult rats maintained on a daily feeding schedule continue to display an increased anticipatory activity for several days after the schedule has been altered (Bolles \& Moot, 1973; Aschoff pers. comm.). Our findings support the idea that the internal signals for anticipatory behaviour associated with feeding may be closely related to the circadian system (ARMSTRONG, 1980). The anticipatory uncovering may represent a circadian rhythm itself, even at this very early age. The poor pre-nursing exposure of pups on day 1 was to be expected as the nursing entry of the doe was experimentally determined. However, pups generally exposed for nursing the following day. This and other questions relating to the development of the circadian rhythm are presently under investigation.

\section{SUMMARY}

Domestic rabbit pups (22 litters of 6 pups each) were raised in plexiglass nest boxes, and their behaviour was studied under various experimental conditions during the first 14 days of life.

1. Rabbit pups show a stereotyped pattern of behaviour closely associated with the once daily nursing visit of the doe until they start to leave the nest on day 13 .

2. One to two hours before nursing pups group tightly together and become exposed from the nest material. In young litters these behaviours appear to improve access to the doe's belly and to shorten the time the doe spends in the nest.

3. Rabbit pups are unusual in that they display a vigorous burst of post-nursing activity, i.e. simultaneous urination followed by digging and burrowing around the nest. This activity is triggered by the nursing act and appears to contribute to thermoregulatory efficiency as an insulating cover is quickly regained.

4. Within about 30 minutes pups reaggregate and remain well covered until the next nursing time.

5. The anticipatory uncovering appears to represent a circadian rhythm, and not to be simply due to hunger, as demonstrated in isolated litters deprived of one nursing. 
6. Presumably the less time wild does spend in the nursery burrow the less chance there is of predators trapping them or finding the young. The ability of the pups to anticipate the nursing and the their thermoregulatory self-sufficiency may contribute to shortening the time rabbit does must spend in the nest.

\section{REFERENCES}

Alberts, J. R. (1978). Huddling by rat pups: Group behavioral mechanisms of temperature regulation and energy conservation. - J. Comp. Psychol. 92, p. 231-245.

Armstrong, S. (1980). A chronometric approach to the study of feeding behavior. Neurosci. Biobehav. Rev. 4, p. 27-53.

Aschoff, J. (1981). Pers. communication.

Bolles, R. C. \& Moot, S. A. (1973). The rat's anticipation of two meals a day. - J. Comp. Physiol. Psychol. 83, p. 510-514.

Cross, B. A. \& Harris, G. W. (1978). The role of the neurohypophysis in the milkejecting reflex. - J. Endocrinol. 8, p. 148-161.

Deutsch, J. A. (1957). Nest building behaviour of domestic rabbits under semi-natural conditions. - Brit. J. Animal Behav. 5, p. 53-54.

Ganong, W. F. (1971). Review of Medical Physiology. - Los Altos, California. Lange Medic. Publ.

Gottlieb, G. (1971). Ontogenesis of sensory function in birds and mammals. - In: The Biopsychology of development (Tobach, E., Aronson, L. R. \& Shaw, E., eds). New York. Academic Press.

Hays, W. L. (1963). Statistics. - London. Holt, Rinehart and Winston.

Hull, D. (1965). Oxygen consumption and body temperature of newborn rabbits and kittens exposed to cold. - J. Physiol. 177, p. 192-202.

- \& Segall, M. M. (1965a). The contribution of brown adipose tissue to heat production in the new-born rabbit. - J. Physiol. 181, p. 449-457.

- $\&$ \& - (1965b). Sympathetic nervous control of brown adipose tissue and heat production in the newborn rabbit. J. Physiol. 181, p. 458-467.

JeDDI, E. (1971). Thermoregulatory efficiency of neaonatal rabbit search for fur comfort contact. - Int. J. Biometereol. 15, p. 337-341.

KRAFT, R. (1979a). Vergleichende Verhaltensstudien an Wild- und Hauskaninchen. I. Das Verhaltensinventar von Wild- und Hauskaninchen. - Zeitschr. Tierzücht. Züchtungsbiol. 95, p. 140-162.

- - (1979b). Idem. II. Quantitative Beobachtungen zum Sozialverhalten. - Zeitschr. Tierzücht. Züchtungsbiol. 95, p. 165-179.

LeOnard, C. M. (1974). Thermotaxis in golden hamster pups. - J. Comp. Physiol. Psychol. 86, p. 458-469.

Lincoln, D. W. (1974). Suckling: A time-constant in the nursing behaviour of the rabbit. - Physiol. Behav. 13, p. 711-714.

Мүкутошусz, R. (1968). Territorial marking by rabbits. - Sci. Amer. 218, p. 116-126.

- - \& Dudzinski, M. L. (1972). Aggressive and protective behaviour of adult rabbits Oryctolagus cuniculus (L) towards juveniles. - Behaviour 43, p. 97-120.

Ripisardi, S. C., Chow, K. L. \& Mathrers, I. H. (1975). Ontogenesis of receptive field characteristics in the dorsal lateral geniculate nucleus of the rabbit. - Exp. Brain Res. 22, p. 295-305.

Rongstad, O. J. \& Tester, J. R. (1971). Behavior and maternal relations of young snowshoe hares. - J. Wildlife Management 35, p. 338-346.

Rosenblatt, J. S. (1976). Stages in the carly behavioural development of altricial young of selected species of non-primate mammals. - In: Growing points in ethology (Batrason, P.P. G. \& Hinde, R. A., eds). Cambridge. Cambridge Univ. Press, p. $345-383$. 
Satinoff, E., McEwen, G. N. \& Williams, B. A. (1976). Behavioral fever in newborn rabbits. - Science 193, p. 1139-1140.

Siegel, S. (1956). Nonparametric Statistics for the Behavioral Sciences. London. McGraw-Hill.

VENGE, O. (1963). The influence of nursing behaviour and milk production on early growth in rabbits. - Animal Behav. 11, p. 500-506.

Wishaw, I. Q., Flannigan, K. P. \& Barnsley, R. H. (1979). Development of tonic immobility in the rabbit: Relation to body temperature. - Developm. Psychobiol. 12 , p. $595-605$.

Worden, A. N. \& Leahy, J. S. (1962). The behaviour of rabbits. - In: The behaviour of domestic animals (Hafez, E. S. E., ed.). London. Bailliere, Tindall \& Cox. p. $397-414$.

Zarrow, M. X., Sawin, P. B., Ross, S. \& Denenberg, V. H. (1962). Maternal behavior and its endocrine basis in the rabbit. In: Roots of behavior (BLIss, E. L., ed.). New York. Harper and Brothers. p. 187-197.

- - Denenberg, V. H. \& Anderson, C. O. (1965). Rabbit: Frequency of suckling in the pup. - Science 150, p. 1835-1836.

\section{ZUSAMMENFASSUNG}

Neugeborene Hauskaninchen (22 Würfe mit je sechs Jungen) wurden in Plexiglas Nestkästen aufgezogen und ihr Verhalten wurde während der ersten 14 Lebenstage beobachtet und experimentell untersucht.

1. Kaninchenjunge zeigen einen stereotypen Rhythmus von Verhaltensweisen, die eng mit der Ankunft der Mutter und dem täglich nur einmal stattfindenden Säugen verknüpft sind.

2. Ein bis zwei Stunden vor dem Säugen drängen sich die Jungen eng aneinander und verlieren dabei die sie bedeckende Schicht aus Neptmaterial. Dieses Verhalten begünstigt anscheinend sehr junge Kaninchen den Bauch der Mutter zu erreichen und scheint auch den Aufenthalt der Mutter im Nest zu verkürzen.

3. Ungewöhnlich ist die kurze, aber heftige Aktivitätsperiode der Kaninchenjungen nach dem Säugen: sie urinieren simultan, graben und wühlen sich durch das Nest. Diese Aktivität wird durch das Säugen ausgelöst und trägt anscheinend zu thermoregulatorischer Leistungsfähigkeit bei, da u.a. eine isolierende Bedeckung schnell wieder erlangt wird.

4. Innerhalb von 30 Minuten kommen die Jungen wieder zusammen und bleiben bis zum nächsten Säugen mit Nestmaterial bedeckt.

5. Das antizipatorische Aufdecken scheint einem circadianen Rhythmus zu folgen und nicht einfach durch Hunger bedingt zu sein, wic an isolierten, nicht gesäugten Würfen gezeigt wurde.

6. Es wird angenommen, daß für Freßfeinde die Chance Kaninchenmütter oder -junge im Bau zu fangen umso geringer ist, je kürzer sich die Mütter dort aufhalten. Die Fähigkeit der Jungen den Säugetermin zu antizipieren und ihren Wärmebedarf selbst ausreichend zu regeln, dürften dazu beitragen den Aufenthalt der Kaninchenmütter im Nest zu verkürzen. 